\title{
The influence of oxygen and nitrogen contamination on the densification behavior of cryomilled copper powders during spark plasma sintering
}

\author{
Haiming Wen $\cdot$ Yonghao Zhao $\cdot$ Zhihui Zhang $\cdot$ \\ Osman Ertorer • Shaoming Dong • Enrique J. Lavernia
}

Received: 30 September 2010/Accepted: 7 December 2010/Published online: 30 December 2010

(C) The Author(s) 2010. This article is published with open access at Springerlink.com

\begin{abstract}
It has been found difficult to fully densify some mechanically milled pure metal powders by spark plasma sintering (SPS). In this study, the densification behavior of cryomilled, nanostructured (NS) Cu powders during SPS was related to changes to the chemistry of the powders. The results showed that the presence of very small amounts of $\mathrm{O}$ and $\mathrm{N}$ in the powders, which were introduced during cryomilling and handling, significantly influenced the densification response. Moreover, reduction/removal of $\mathrm{O} / \mathrm{N}$ via thermal annealing of the powders before SPS led to complete densification of the powders during subsequent SPS. The mechanisms responsible for this behavior were ascertained: $\mathrm{O}$ and $\mathrm{N}$ existed in the cryomilled powders in the form of thermally unstable compounds, and the subsequent thermal decomposition of these compounds during SPS generated the gaseous species, leading to porosity formation and incomplete densification; annealing of the powders before SPS removed the gases which resulted from thermal decomposition, thereby facilitating complete consolidation during subsequent SPS.
\end{abstract}

\section{Introduction}

A "two-step" approach, in which nanocrystalline (nc) powders are first prepared and then consolidated via various techniques, is widely used to produce bulk

H. M. Wen $(\bowtie) \cdot$ Y. H. Zhao · Z. H. Zhang · O. Ertorer ·

E. J. Lavernia

Department of Chemical Engineering and Materials Science,

University of California at Davis, Davis, CA 95616, USA

e-mail: hmwen@ucdavis.edu

S. M. Dong

Shanghai Institute of Ceramics, Chinese Academy of Sciences,

Shanghai 200050, China nanostructured (NS) metals [1-3]. Mechanical milling, especially cryomilling (milling in a cryogenic liquid such as liquid nitrogen), represents an approach that can be used to generate a large quantity of nc metallic powders in a single batch $[4,5]$. However, a drawback associated with mechanical milling is that contamination is unavoidable from the milling media, atmosphere, and process control agents (PCAs) [6]. Spark plasma sintering (SPS), which involves rapid heating of powders by pulsed DC current with the simultaneous application of external pressure, is an efficient consolidation technique which enables densification of nc powders at significantly lower temperatures within much shorter time [7-9]. The decided advantages of SPS over conventional sintering methods including hotpressing mainly derive from the application of electric field/current, which provides high heating rate and enhances mass transport by increasing point defect concentration, reducing activation energy for migration of defects, or enhancing mobility of the defects [10, 11]. Published articles on SPS include experimental studies of process variables, and theoretical model analyses of densification mechanisms during SPS [12-16].

Inspection of the scientific literature reveals that nc metallic powders of various compositions have been successfully produced by mechanical milling or cryomilling, followed by consolidation via SPS [17-25]. However, changes to the chemistry of the powders during milling, and particularly during SPS, are seldom discussed, and moreover, the final relative density of SPS-consolidated bulk material is often calculated and reported on the basis of the theoretical density of the pure metal or alloy with a nominal composition (i.e., ignoring the chemistry changes that are induced by the milling environment and during SPS). This lack of attention to the chemistry raises two important questions. First, is there a change during SPS to 
the chemistry of the milled powders with impurities introduced during milling? Second, what is the influence of this chemistry change on the densification response during SPS?

Despite of the successful densification of various milled metallic powders via SPS, it has been found that it is difficult to fully densify cryomilled powders of some pure metals such as $\mathrm{Al}, \mathrm{Ni}$, and $\mathrm{Cu}$. In related studies, a high temperature of $873 \mathrm{~K}$, which represents $93.5 \%$ of $\mathrm{Al}$ 's melting point, was used to fully densify mechanically milled Al powders by SPS [23]. In this study, the authors demonstrate that failure to attain complete densification of cryomilled $\mathrm{Cu}$ powders during SPS is not related to the selection of densification parameters (e.g., pressure, temperature, heating rate, holding time, etc.), but instead it is related to changes in the chemistry of the powders. The adsorption of $\mathrm{N}_{2}$, and $\mathrm{O}_{2}$ at powders surfaces and subsequent formation of thermally unstable compounds during milling and handling, and the subsequent thermal decomposition of these compounds during SPS generating gaseous species, led to porosity formation, and consequently, incomplete densification. Complete densification of the cryomilled $\mathrm{Cu}$ powders was achieved, only after careful thermal degassing before SPS. The associated mechanisms responsible for this behavior are described and discussed.

\section{Experimental}

Commercially pure (purity $99.9 \%$ on metal basis) coarsegrained $\mathrm{Cu}$ powders purchased from Alfa Aesar (Ward Hill, Massachusetts) with particle sizes of 44-149 $\mu \mathrm{m}$ were cryomilled for $8 \mathrm{~h}$ in liquid nitrogen with a stainless-steelball to powder ratio of 30:1, without PCA. Cryomilled and unmilled $\mathrm{Cu}$ powders were consolidated using a SPS-515S apparatus (SPS Syntex Inc., Kanagawa, Japan) at different sintering temperatures (the accuracy of temperature measurement was $0.1{ }^{\circ} \mathrm{C}$ ) for $5 \mathrm{~min}$ with a heating rate of $100{ }^{\circ} \mathrm{C} / \mathrm{min}$, using a graphite die of $20 \mathrm{~mm}$ in diameter. The initial pressure applied was 12.5 or $100 \mathrm{MPa}$ and the holding pressure at sintering temperatures was always $100 \mathrm{MPa}$ (the accuracy of load was $0.3 \mathrm{MPa}$ ). Note that $12.5 \mathrm{MPa}(4 \mathrm{kN})$ is the lowest load which can be applied in the continuous displacement mode for our SPS equipment. The vacuum pressures, with an accuracy of $0.001 \mathrm{~Pa}$, as a function of temperature were recorded by the components attached to the SPS apparatus. In some other experiments, cryomilled $\mathrm{Cu}$ powders were heat treated in a vacuum furnace at 550 or $750{ }^{\circ} \mathrm{C}$ for 20 min with a heating rate of $20{ }^{\circ} \mathrm{C} / \mathrm{min}$, and then consolidated by SPS at 550 or $750{ }^{\circ} \mathrm{C}$ using an initial pressure of $12.5 \mathrm{MPa}$. The relative density of the SPS'ed bulk samples was determined in distilled water by the Archimedes method, which has an error not higher than $0.2 \%$. Impurity contents (primarily $\mathrm{O}$ and $\mathrm{N}$ ) in unmilled, as-cryomilled and heat-treated cryomilled $\mathrm{Cu}$ powders, and SPS'ed bulk samples were analyzed in a commercial laboratory (Luvak Inc., Boylston, MA) using the method of inert gas fusion and following the ASTM E 1019-08 standard. Transmission electron microscopy (TEM) was used to characterize the microstructures of as-cryomilled, $550{ }^{\circ} \mathrm{C}$ heat-treated cryomilled $\mathrm{Cu}$ powders and SPS'ed bulk samples. The procedures for preparing TEM specimens are described as follows. For powders, epoxy was used to glue powders together into a bulk sample, and thin foils were obtained by grinding the bulk sample. In the case of SPS'ed bulk samples, thin foils were sectioned from the samples. The TEM specimens were obtained by mechanically grinding and dimpling the thin foils to a thickness of $\sim 10 \mu \mathrm{m}$, and further thinning to electron transparency using a Gatan PIPS 691 ion milling system. TEM observations were carried out on a Philips CM12 microscope operating at $120 \mathrm{kV}$. A thermogravimetric analysis (TGA)-mass spectrometry (MS) coupling technique which consisted of a Netzsch TG 209F1 thermogravimetric analyzer with a sensitivity of $0.1 \mu \mathrm{g}$ and a QMS 403 mass spectrometer with a resolution of ion current measurement of $0.01 \mathrm{pA}$ was used to study the possible decomposition of impurities in the cryomilled $\mathrm{Cu}$ powders during heating. The sample was placed in an alumina crucible and heated at a rate of $10{ }^{\circ} \mathrm{C} / \mathrm{min}$ from room temperature to $850{ }^{\circ} \mathrm{C}$ in an argon flow with ultra high purity $(99.999 \%)$ with a flow rate of $20 \mathrm{~mL} / \mathrm{min}$.

\section{Results and discussion}

It was found that it was difficult to densify cryomilled $\mathrm{Cu}$ powders, as indicated by the density results of SPS'ed bulk samples shown in Fig. 1 (note that for these sets of SPS experiments, the initial pressure applied was $12.5 \mathrm{MPa}$ ). With increasing sintering temperature, the density increased slowly and reached only $94.5 \%$ at $750{ }^{\circ} \mathrm{C}$ ( $\sim 80 \%$ of $\mathrm{Cu}$ 's melting point), which was surprisingly low. Interestingly, SPS at $750{ }^{\circ} \mathrm{C}$ of unmilled $\mathrm{Cu}$ powders using exactly the same parameters resulted in a final density of $99 \%$. From statistical TEM analysis, the cryomilled $\mathrm{Cu}$ powders have an average grain size of $45 \mathrm{~nm}$ [26]. In principle, densification should be enhanced by the presence of the nanostructure, given that diffusion pathways at the grain boundaries are increased and the driving force for densification is enhanced. However, the authors observed that densification of the cryomilled $\mathrm{Cu}$ powders is even more difficult than that of the unmilled coarse-grained $\mathrm{Cu}$ powders, indicating that there may be some special structural/compositional characteristics associated with the cryomilled $\mathrm{Cu}$ powders. 


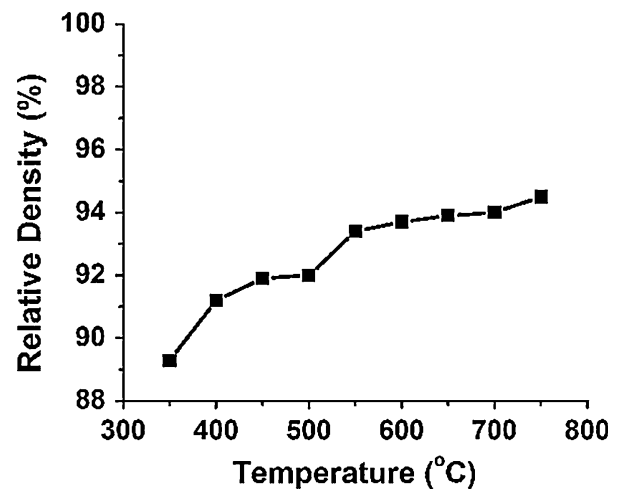

Fig. 1 Density of SPS'ed cryomilled $\mathrm{Cu}$ at different sintering temperatures

The vacuum pressure change during SPS as a function of temperature is rarely reported. However, it was recorded in this study, and the results are shown in Fig. 2 for SPS of cryomilled $\mathrm{Cu}$ powders at $750{ }^{\circ} \mathrm{C}$ with an initial pressure of $12.5 \mathrm{MPa}$ applied which resulted in a final density of $94.5 \%$. It can be seen that there was significant vacuum pressure change during SPS. Interestingly, there are two sharp peaks in the vacuum pressure curve at $\sim 550$ and $\sim 705{ }^{\circ} \mathrm{C}$, respectively, indicating release of gaseous species, which may have an influence on the SPS process.

The initial pressure applied during SPS was found to have a significant influence on the final density of the consolidated bulk sample. When an initial pressure of $100 \mathrm{MPa}$ was applied, the final density of $750{ }^{\circ} \mathrm{C}$ SPS'ed cryomilled $\mathrm{Cu}$ was $91.0 \%$, contrasted by $94.5 \%$ achieved for it when an initial pressure of $12.5 \mathrm{MPa}$ was used. Notably, when an initial pressure of $100 \mathrm{MPa}$ was applied, there was almost no vacuum pressure change during SPS, contrasted by the significant change in vacuum pressure shown above when adopting an initial pressure of 12.5 MPa. The sintering curves (displacement versus temperature) of the SPS when an initial pressure of 100 and

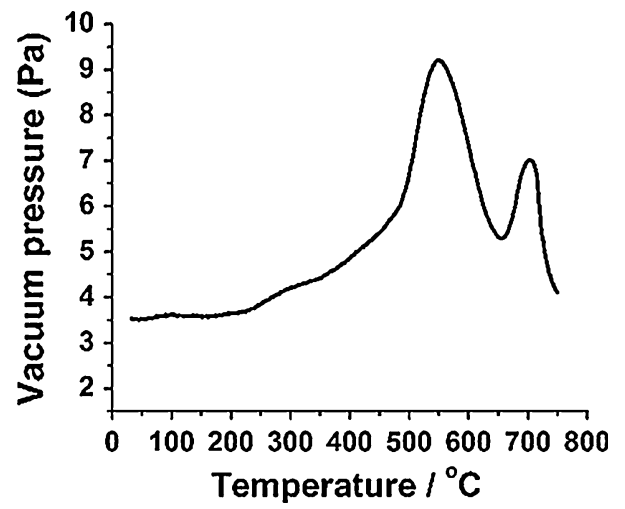

Fig. 2 Vacuum pressure as a function of temperature during SPS of cryomilled $\mathrm{Cu}$ powders with an initial pressure of $12.5 \mathrm{MPa}$ (only temperature ramping stage is plotted)
12.5 MPa was applied are shown in Fig. 3. From the displacement-temperature curves, it can be seen that when an initial pressure of $100 \mathrm{MPa}$ was applied, the densification of powders was fast during the earlier stage of the sintering, as indicated by the large slope of the curve between $\sim 50$ and $\sim 400{ }^{\circ} \mathrm{C}$. The displacement reached a plateau at $\sim 515{ }^{\circ} \mathrm{C}$, and decreased after the plateau. The lower-temperature densification can be explained by the contribution of high pressure to increasing the driving force for sintering, which leads to a decrease in the sintering temperature [10]. The decrease of displacement after the plateau was primarily attributed to gas generation. It is noted that densification took place at temperatures lower than the gas-generation temperatures of the powders. Consequently, almost all gases generated during SPS were trapped in the powder compact. The trapped gases contributed to more porosity in the final consolidated bulk and accordingly significant reduction in the density. By contrast, when an initial pressure of $12.5 \mathrm{MPa}$ was used, significant densification did not take place until a sintering pressure of $100 \mathrm{MPa}$ was applied at the sintering temperature $\left(750{ }^{\circ} \mathrm{C}\right)$. Therefore, gases generated from the powders can be released, which contributed to a higher density. These results are in agreement with some reports in the literature [27-29] that lower initial pressure used for SPS led to higher density of consolidated bulk $\mathrm{Cu}$. However, in those reports, in which vacuum pressure change during SPS was not monitored, the underlying mechanism was not elucidated. In addition, for Fig. 3, it should be noted that the initial pressure was applied at room temperature and there was a displacement right after the pressure application, but this displacement was zeroed before the temperature ramp-up and further displacements after heating were recorded and plotted in Fig. 3. In the case of the initial pressure of $100 \mathrm{MPa}$, the initial displacement zeroed out was much larger than that for the initial pressure of $12.5 \mathrm{MPa}$. This fact explains why in Fig. 3, the peak displacement for the former is much smaller than that for the latter.

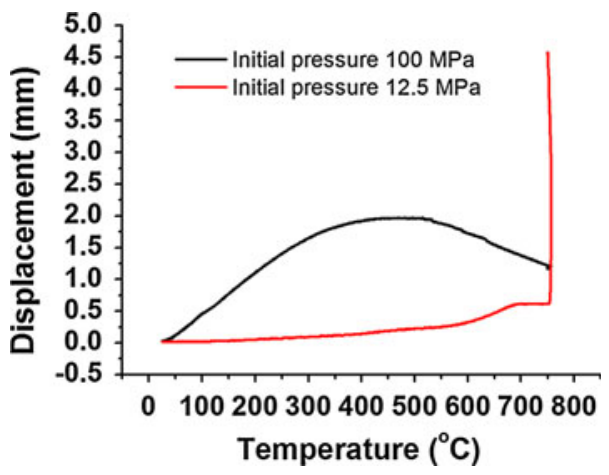

Fig. 3 Displacement as a function of temperature during SPS of cryomilled $\mathrm{Cu}$ powders with different initial pressures of 12.5 and $100 \mathrm{MPa}$ (both temperature ramping and holding stages are plotted) 
In view of the results of this study showing gas generation during SPS, which may influence the densification response, the authors studied the degassing response of the cryomilled $\mathrm{Cu}$ powders before SPS processing to see if it has any influence on the subsequent SPS densification. The results showed that SPS at $750{ }^{\circ} \mathrm{C}$ (initial pressure 12.5 $\mathrm{MPa}$ ) of cryomilled $\mathrm{Cu}$ powders which were heat treated at $750{ }^{\circ} \mathrm{C}$ before SPS resulted in no vacuum pressure change during SPS and a final density of $98.6 \%$, which represents a dramatic improvement over the density of 94.5\% achieved by SPS of as-cryomilled $\mathrm{Cu}$ powders using exactly the same parameters. The absence of a vacuum pressure change during SPS indicated that gases which would be generated during SPS had been removed during thermal annealing in vacuum, which resulted in nearly full density of SPS'ed bulk sample. Notably, when using a sintering temperature of $550{ }^{\circ} \mathrm{C}$ for SPS of $750{ }^{\circ} \mathrm{C}$ annealed cryomilled $\mathrm{Cu}$ powders, the final density was 98.5\%. In addition, when the cryomilled $\mathrm{Cu}$ powders were heat treated at $550{ }^{\circ} \mathrm{C}$ followed by sintering at $550{ }^{\circ} \mathrm{C}$ by SPS, the final density was $94.4 \%$. Therefore, only when the annealing temperature exceeded the higher peak temperature for gas generation, which was $\sim 705{ }^{\circ} \mathrm{C}$ (see Fig. 2), was complete densification of the annealed cryomilled $\mathrm{Cu}$ powders achieved.

Gas generation from the powders during heating indicates chemistry change of the powders. In order to confirm the presence of chemistry change during heating and its influence on SPS densification, chemical analyses were conducted on unmilled, as-cryomilled and heat-treated cryomilled $\mathrm{Cu}$ powders as well as on SPS'ed bulk samples. $\mathrm{O}, \mathrm{N}, \mathrm{C}, \mathrm{Fe}, \mathrm{Al}$, and $\mathrm{Cr}$ were analyzed for the as-cryomilled $\mathrm{Cu}$ powders, and their contents in weight percent were $0.512,0.26,0.027,0.064,<0.0005$, and $0.0094 \%$, respectively. Other powders and bulk samples were analyzed for $\mathrm{O}$ and $\mathrm{N}$ contents, and the results are summarized in Table 1. The unmilled powders (Sample \#1) and as-cryomilled powders (Sample \#2) had similar O contents, but there was $0.26 \% \mathrm{~N}$ in the cryomilled powders whereas the $\mathrm{N}$ content in the unmilled powders was negligible. In the SPS'ed unmilled Cu (Sample \#3) which achieved 99.0\% density, the $\mathrm{O}$ content was reduced by $50 \%$ relative to the initial powder (Sample \#1). Notably, in the SPS'ed cryomilled $\mathrm{Cu}$ with $12.5 \mathrm{MPa}$ initial pressure applied during SPS and final density of $94.5 \%$ (Sample \#4), both O and N contents decreased by nearly a half relative to the initial powder (Sample \#2); while in the SPS'ed cryomilled $\mathrm{Cu}$ with initial pressure of $100 \mathrm{MPa}$ and final density of $91.0 \%$ (Sample \#5), both $\mathrm{O}$ and $\mathrm{N}$ contents almost remained unchanged. This difference supports our previous argument that when a high initial pressure was used during SPS, gases were all trapped in the powder compact and resulted in significant reduction in the final density. Interestingly, after the cryomilled powders were annealed at $750{ }^{\circ} \mathrm{C}$ (Sample \#6), the O content was reduced by about $50 \%$, while the $\mathrm{N}$ was almost removed. Subsequent SPS processing (Sample \#7) of the cryomilled powders which were annealed at $750{ }^{\circ} \mathrm{C}$ barely changed the $\mathrm{O}$ content, suggesting that the $\mathrm{O}$ was stabilized, possibly as some type of oxide phase, after annealing in vacuum. The nearly full density achieved for the SPS'ed annealed cryomilled $\mathrm{Cu}$ (Sample \#7) indicates that annealing under vacuum of the cryomilled powders effectively removes gaseous species which result from decomposition of thermally unstable species, thereby facilitates complete consolidation during subsequent SPS. In contrast, although when a low initial pressure is applied during SPS of the as-cryomilled powders (Sample \#4), the vacuum and temperature conditions present during SPS did promote removal of some of the gases from the powders; as supported by the chemical analysis results, this was not sufficient for complete densification because part of the gases were still entrapped in the powder compact.

The microstructures of powders and SPS'ed bulk samples were studied by TEM. Figure $4 \mathrm{a}-\mathrm{d}$ shows TEM images of as-cryomilled powders, $550{ }^{\circ} \mathrm{C}$-annealed powders, $600{ }^{\circ} \mathrm{C}$ SPS'ed cryomilled $\mathrm{Cu}$, and $550{ }^{\circ} \mathrm{C}$ SPS'ed $750{ }^{\circ} \mathrm{C}$-annealed cryomilled $\mathrm{Cu}$. It is evident that the as-cryomilled powders have equiaxed grains of $\sim 45 \mathrm{~nm}$ in size, with very few nanopores present between grains. Note that the average size of powder particles is $\sim 50 \mu \mathrm{m}$ because of significant cold welding during cryomilling

Table 1 Chemical analysis results of $\mathrm{O}$, and $\mathrm{N}$ contents in various powders and SPS'ed bulk samples

\begin{tabular}{|c|c|c|c|}
\hline No. & Sample identification & $\mathrm{O}(\mathrm{wt} \%)$ & $\mathrm{N}(\mathrm{wt} \%)$ \\
\hline 1 & Unmilled $\mathrm{Cu}$ powders & 0.45 & 0.004 \\
\hline 2 & Cryomilled $\mathrm{Cu}$ powders & 0.512 & 0.26 \\
\hline 3 & $750{ }^{\circ} \mathrm{C}$ SPS'ed unmilled $\mathrm{Cu}$, initial pressure $12.5 \mathrm{MPa}, 99.0 \%$ & 0.225 & 0.002 \\
\hline 4 & $750{ }^{\circ} \mathrm{C}$ SPS'ed cryomilled $\mathrm{Cu}$, initial pressure $12.5 \mathrm{MPa}, 94.5 \%$ & 0.281 & 0.14 \\
\hline 5 & $750^{\circ} \mathrm{C}$ SPS'ed cryomilled $\mathrm{Cu}$, initial pressure $100 \mathrm{MPa}, 91.0 \%$ & 0.485 & 0.25 \\
\hline 6 & $750^{\circ} \mathrm{C}$-annealed cryomilled $\mathrm{Cu}$ powders & 0.247 & 0.025 \\
\hline 7 & $750{ }^{\circ} \mathrm{C}$ SPS'ed $750^{\circ} \mathrm{C}$-annealed cryomilled $\mathrm{Cu}$, initial pressure $12.5 \mathrm{MPa}, 98.6 \%$ & 0.227 & 0.022 \\
\hline
\end{tabular}


Fig. 4 TEM images of a as-cryomilled $\mathrm{Cu}$ powders, b $550{ }^{\circ} \mathrm{C}$-annealed $\mathrm{Cu}$ powders, c $600{ }^{\circ} \mathrm{C}$ SPS'ed cryomilled $\mathrm{Cu}$, d $550{ }^{\circ} \mathrm{C}$ SPS'ed $750{ }^{\circ} \mathrm{C}$ annealed cryomilled $\mathrm{Cu}$
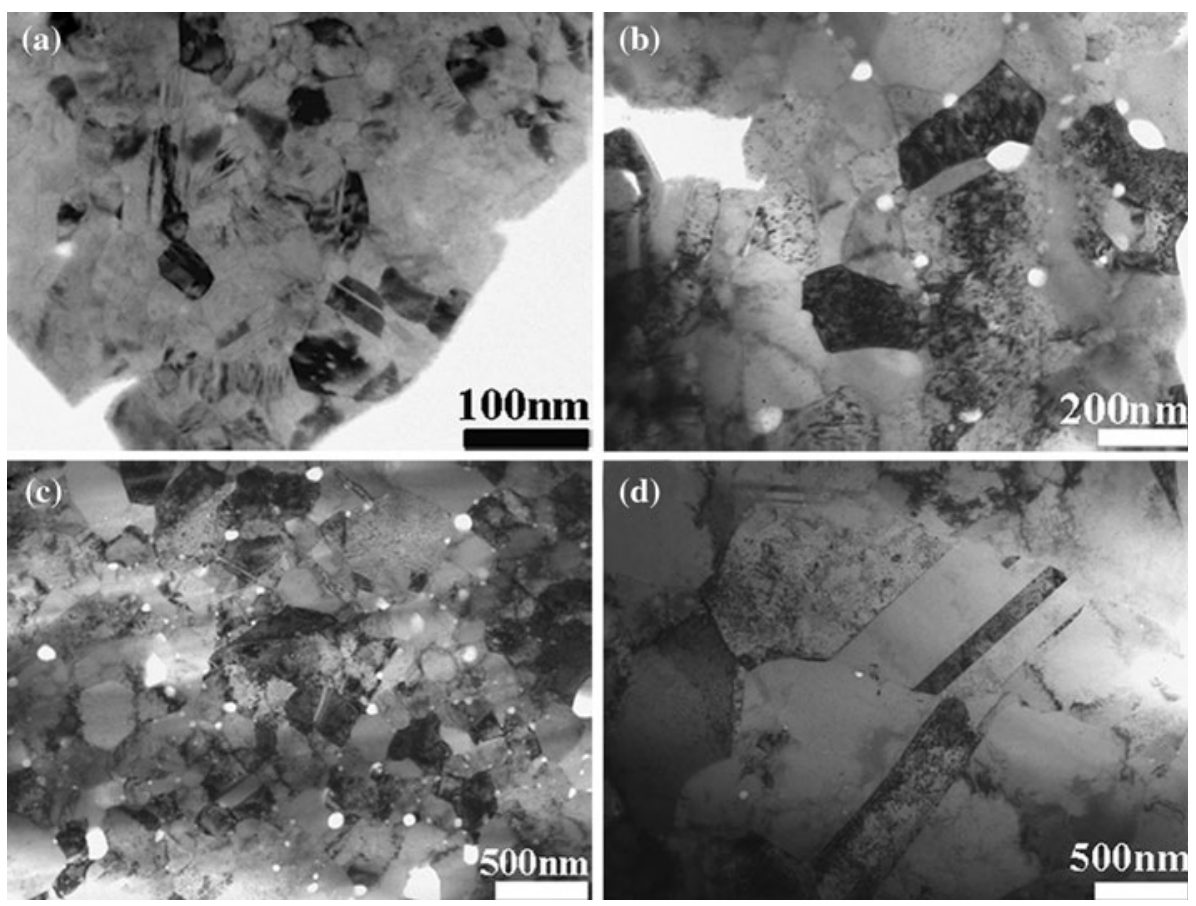

[24]. In contrast, after heat treatment at $550{ }^{\circ} \mathrm{C}$, a high concentration of pores is evident, primarily at grain boundaries, and the grain size grows to $\sim 200 \mathrm{~nm}$. The presence of pores can be rationalized on the basis of gas release at $\sim 550{ }^{\circ} \mathrm{C}$ during annealing (see Fig. 2). Similarly, a number of pores can be seen in the $600{ }^{\circ} \mathrm{C}$ SPS'ed cryomilled $\mathrm{Cu}$ sample whose density is $93.7 \%$ (see Fig. 1), with an average grain size of $\sim 300 \mathrm{~nm}$. In contrast, pores are barely evident in the sample obtained via SPS at $550{ }^{\circ} \mathrm{C}$ of $750{ }^{\circ} \mathrm{C}$-annealed cryomilled $\mathrm{Cu}$ powders, indicating nearly full density, which is consistent with the density value $(98.5 \%)$. Because gases were released at $\sim 550$ and $\sim 705^{\circ} \mathrm{C}$, it can be anticipated that large quantity of pores were generated in the $750{ }^{\circ} \mathrm{C}$-annealed cryomilled powders. However, these pores were successfully eliminated during SPS. The large grain size $(1-2 \mu \mathrm{m})$ of this sample is primarily attributed to the high temperature annealing at $750{ }^{\circ} \mathrm{C}$.

Simultaneous TGA and MS studies were conducted to provide fundamental insight into the phenomena of gas generation during heating of cryomilled $\mathrm{Cu}$ powders. TGA analysis can provide quantitative information about weight loss during heating due to the release of gaseous species, and MS is able to qualitatively ascertain the chemical nature of these gaseous species. The TGA-MS results are shown in Fig. 5, in which the sample weight in percent (TG) as well as the currents of various fragment ions are plotted versus temperature. From the TG curve, there are two temperature ranges of weight loss, namely, $\sim 300-600{ }^{\circ} \mathrm{C}$ and $\sim 670-800{ }^{\circ} \mathrm{C}$. From the dynamic TG (weight loss per minute) curve which is not shown in the figure, the peak weight loss rate is reached at 530 and $720{ }^{\circ} \mathrm{C}$, respectively, for the two temperature ranges of weight loss. For the ion current curves, the numbers indicated besides the curves are the mass number (mass/ charge ratio) of ions. Based on the relation of MS mass number-fragment ions-parent molecules [30] and the chemical composition of the cryomilled $\mathrm{Cu}$ powders, mass numbers of $14,28,16,32$, and 46 correspond to $\mathrm{N}^{+}, \mathrm{N}_{2}{ }^{+}$, $\mathrm{O}^{+}, \mathrm{O}_{2}{ }^{+}$, and $\mathrm{NO}_{2}{ }^{+}$, respectively, and these fragment ions originate from the parent molecules of $\mathrm{N}_{2}, \mathrm{~N}_{2}, \mathrm{O}_{2}, \mathrm{O}_{2}$, and $\mathrm{NO}_{2}$, respectively. Therefore, during heating of the cryomilled $\mathrm{Cu}$ powders, $\mathrm{N}_{2}, \mathrm{O}_{2}$, and $\mathrm{NO}_{2}$ are generated and released from the powders.

It can be seen that there is a relatively broad peak at $\sim 530{ }^{\circ} \mathrm{C}$ in the ion current curves of 16 and 32 , which is attributed to release of $\mathrm{O}_{2}$. The generation of $\mathrm{O}_{2}$ at this temperature should be due to decomposition of $\mathrm{CuO}$ to $\mathrm{Cu}_{2} \mathrm{O}$. The $\mathrm{Cu}$ powders were oxidized in laboratory air at room temperature during handling. The oxidation products of $\mathrm{Cu}$ in the air at room temperature include $\mathrm{Cu}_{2} \mathrm{O}$ and $\mathrm{CuO}$ $[31,32] . \mathrm{CuO}$ is decomposed to $\mathrm{Cu}_{2} \mathrm{O}$ at different temperatures under different $\mathrm{O}_{2}$ pressures, and when the $\mathrm{O}_{2}$ pressure is $\sim 10^{-2} \mathrm{~Pa}$, the decomposition temperature of $\mathrm{CuO}$ is $\sim 520{ }^{\circ} \mathrm{C}[33,34]$, which is in agreement with the release of $\mathrm{O}_{2}$ at $\sim 530{ }^{\circ} \mathrm{C}$ during TGA-MS measurement (the thermogravimetric analyzer can be evacuated down to $\left.10^{-2} \mathrm{~Pa}\right)$. 


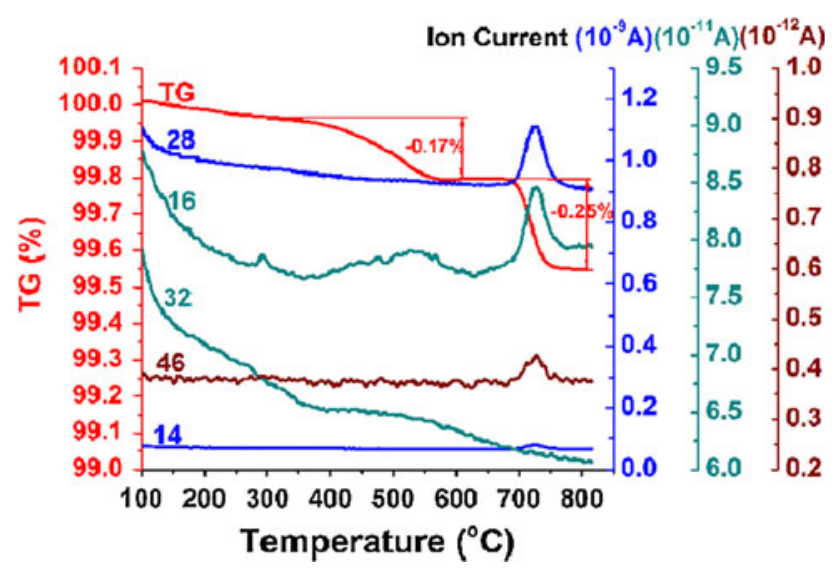

Fig. 5 TGA-MS results of the cryomilled $\mathrm{Cu}$ powders. The sample weight in percent (TG) and the currents of fragment ions are plotted versus temperature. On the TG curve, the values of weight losses are labeled for the two temperature ranges of weight loss. On the ion current curves, the numbers indicated beside the curves are the mass/ charge ratio of ions. The three vertical axises for ion current from left to right correspond to current curves of 28-14, 32-16, and 46, respectively

Notably, there is a sharp peak at $\sim 720{ }^{\circ} \mathrm{C}$ in the ion current curves of $14,28,16$, and 46 , indicating simultaneous release of $\mathrm{N}_{2}, \mathrm{O}_{2}$, and $\mathrm{NO}_{2}$ from the powders at this temperature. This peak cannot be attributed to desorption of absorbed gases from the powders, considering the high temperature. The sharp peaks at $\sim 720{ }^{\circ} \mathrm{C}$ in the ion current curves and the narrow temperature range $(\sim 670$ $800^{\circ} \mathrm{C}$ ) for weight loss in the TG curve (with a maximum weight loss rate at $\sim 720^{\circ} \mathrm{C}$ ) indicate thermal decomposition of some chemical compound(s). $\mathrm{Cu}_{3} \mathrm{~N}$, if it is present in the powders, decomposes at $\sim 300{ }^{\circ} \mathrm{C}[35,36]$. In addition, $\mathrm{Cu}_{2} \mathrm{O}$ is stable and will not decompose to $\mathrm{Cu}$ up to a temperature of $1000{ }^{\circ} \mathrm{C}[33,34]$. Furthermore, decomposition of $\mathrm{Cu}\left(\mathrm{NO}_{3}\right)_{2}$, if it is present in the powders, takes place below $300{ }^{\circ} \mathrm{C}$ [37]. In the powder diffraction file database of The International Center for Diffraction Data, the only other $\mathrm{Cu}-\mathrm{N}-\mathrm{O}$ ternary compound besides $\mathrm{Cu}\left(\mathrm{NO}_{3}\right)_{2}$ is $\mathrm{Cu}_{8} \mathrm{O}_{8}\left(\mathrm{NO}_{3}\right)$. However, it is cited from a private communication, and it cannot be verified from the open literature. No other $\mathrm{Cu}-\mathrm{N}-\mathrm{O}$ compounds have been reported in the literature. Therefore, the authors propose that there is an unidentified $\mathrm{Cu}-\mathrm{O}-\mathrm{N}$ ternary compound formed in the cryomilled $\mathrm{Cu}$ powders, and this compound decomposes at $\sim 720{ }^{\circ} \mathrm{C}$, releasing $\mathrm{N}_{2}, \mathrm{O}_{2}$, and $\mathrm{NO}_{2}$ simultaneously. The origin of this particular compound is not presently known although one can speculate that its formation may be due to the reaction of $\mathrm{N}_{2}$ and $\mathrm{O}_{2}$ with cryomilled $\mathrm{Cu}$ powders. Reports available in the literature indicated that $\mathrm{Al}$ can react with $\mathrm{N}_{2}$ and/or $\mathrm{O}_{2}$ during cryomilling and form $\mathrm{AlN}, \mathrm{Al}_{2} \mathrm{O}_{3}$, and O-containing AlN [38-40]. Cryomilled $\mathrm{Cu}$ powders can be exposed to $\mathrm{N}_{2}$ and $\mathrm{O}_{2}$ during both cryomilling and handling in laboratory air. The reaction may be initiated by adsorption (chemisorption) of $\mathrm{O}_{2}$ and $\mathrm{N}_{2}$ on the powder surfaces. The chemisorption of $\mathrm{O}_{2}$ on $\mathrm{Cu}$ surfaces has been well documented [41]. Under ambient conditions, $\mathrm{N}_{2}$ does not interact with $\mathrm{Cu}$ surfaces, due to the strong $\mathrm{N}-\mathrm{N}$ bond, so the adsorption of $\mathrm{N}$ on $\mathrm{Cu}$ surfaces has been achieved typically by $\mathrm{N}$-ion bombardment [42, 43]. However, the special structure (e.g., high surface area) and/or energy state (e.g., highly nonequilibrium state) induced by cryomilling may enable adsorption of $\mathrm{N}_{2}$ on cryomilled $\mathrm{Cu}$ powder surfaces. The chemisorption of $\mathrm{O}$ and $\mathrm{N}$ on the cryomilled $\mathrm{Cu}$ powder surfaces is accompanied by the breakage of $\mathrm{Cu}-\mathrm{Cu}$ surface bonds and creation of new $\mathrm{Cu}$-adsorbate bonds. Thus, a large degree of restructuring occurs, and new ordered structures are created, with the generation of nuclei. The formation of the $\mathrm{Cu}-\mathrm{N}-\mathrm{O}$ ternary compound advances by the growth of the original nuclei. The mechanism described above is proposed based on the processes of chemisorption of $\mathrm{O}_{2}$ on $\mathrm{Cu}$ surfaces and formation of copper oxides [41]. Further studies are underway to confirm the proposed mechanism for the formation of the $\mathrm{Cu}-\mathrm{N}-\mathrm{O}$ ternary compound and ascertain the formula and structure of the compound.

After the $750{ }^{\circ} \mathrm{C}$ annealing, the $\mathrm{O}$ content in the cryomilled powders is $0.247 \%$. From the TGA-MS analysis described above, after decomposition of $\mathrm{CuO}$ and the $\mathrm{Cu}-\mathrm{O}-\mathrm{N}$ compound during heat treatment of the cryomilled $\mathrm{Cu}$ powders, $\mathrm{O}$ left in the powders is in the form of $\mathrm{Cu}_{2} \mathrm{O}$. Based on these analyses, and considering the existence of $\mathrm{Cu}_{2} \mathrm{O}$, the theoretical density of the SPS'ed $750{ }^{\circ} \mathrm{C}$-annealed cryomilled $\mathrm{Cu}$ can be calculated to be $8.84 \mathrm{~g} / \mathrm{cm}^{3}$. Therefore, the actual relative density of SPS'ed $750{ }^{\circ} \mathrm{C}$-annealed cryomilled $\mathrm{Cu}$ samples should be calculated based on a theoretical density of $8.84 \mathrm{~g} / \mathrm{cm}^{3}$ rather than $8.92 \mathrm{~g} / \mathrm{cm}^{3}$ (theoretical density of pure $\mathrm{Cu}$ ). Accordingly, the actual relative density of the sample obtained by SPS at $550 / 750{ }^{\circ} \mathrm{C}$ of $750{ }^{\circ} \mathrm{C}$-annealed cryomilled $\mathrm{Cu}$ powders is calculated as $99.4 / 99.5 \%$, instead of the nominal value of $98.5 / 98.6 \%$ given before. Therefore, full densification of cryomilled $\mathrm{Cu}$ powders was achieved.

\section{Conclusions}

In summary, it was difficult to fully densify by SPS as-cryomilled $\mathrm{Cu}$ powders which contain $\mathrm{O}$ and $\mathrm{N}$ as primary impurities, because of the generation of gaseous species from the powders and the subsequent entrapment of part of these gases in the powder compact during SPS. TGA-MS studies confirmed the release of gases during heating of the cryomilled $\mathrm{Cu}$ powders: at $\sim 530{ }^{\circ} \mathrm{C}, \mathrm{CuO}$ decomposes into $\mathrm{Cu}_{2} \mathrm{O}$, which generates $\mathrm{O}_{2}$; at $\sim 720{ }^{\circ} \mathrm{C}$, decomposition of a probably new $\mathrm{Cu}-\mathrm{O}-\mathrm{N}$ compound 
takes place, resulting in release of $\mathrm{O}_{2}, \mathrm{~N}_{2}$, and $\mathrm{NO}_{2}$. When the cryomilled powders were heat treated at $750{ }^{\circ} \mathrm{C}$ under vacuum before SPS, gases generated because of thermal decomposition were removed. Subsequent SPS of the $750{ }^{\circ} \mathrm{C}$-annealed cryomilled powders resulted in full density, if the residual $\mathrm{Cu}_{2} \mathrm{O}$ in the material is taken into account. The methodology adopted in this study can be applied to investigate SPS of other mechanically milled metallic powders.

Acknowledgements The authors like to acknowledge the financial support by the Office of Naval Research (Grant number ONR N00014-08-1-0405). The authors thank Haijun Zhou from Shanghai Institute of Ceramics for help with preparation of samples, and Lianlian Jiao from Netzsch Scientific Instruments Trading (Shanghai) Co. Ltd. for assistance with TGA-MS tests.

Open Access This article is distributed under the terms of the Creative Commons Attribution Noncommercial License which permits any noncommercial use, distribution, and reproduction in any medium, provided the original author(s) and source are credited.

\section{References}

1. Meyers MA, Mishra A, Benson DJ (2006) Prog Mater Sci 51:427

2. Zhao YH, Zhan Q, Topping TD, Li Y, Liu W, Lavernia EJ (2010) Mater Sci Eng A 527:1744

3. Mukhtar A, Zhang DL, Kong C, Munroe P (2010) J Mater Sci 45:4594

4. Witkin DB, Lavernia EJ (2006) Prog Mater Sci 51:1

5. Koch CC, Scattergood RO, Youssef KM, Chan EH, Zhu YTT (2010) J Mater Sci 45:4725

6. Zhang DL (2004) Prog Mater Sci 49:537

7. Orru R, Licheri R, Locci AM, Cincotti A, Cao GC (2009) Mater Sci Eng R 63:127

8. Carney CM (2009) J Mater Sci 44:5673

9. Xie YH, Yin S, Hashimoto T, Kimura H, Sato T (2009) J Mater Sci 44:4834

10. Munir ZA, Anselmi-Tamburini U, Ohyanagi M (2006) J Mater Sci 41:763

11. Garay JE, Glade SC, Anselmi-Tamburini U, Asoka-Kumar P, Munir ZA (2004) Appl Phys Lett 85:573

12. Anselmi-Tamburini U, Garay JE, Munir ZA (2005) Mater Sci Eng A 407:24

13. Anselmi-Tamburini U, Gennari S, Garay JE, Munir ZA (2005) Mater Sci Eng A 394:139
14. Chen W, Anselmi-Tamburini U, Garay JE, Groza JR, Munir ZA (2005) Mater Sci Eng A 394:132

15. Olevsky E, Froyen L (2006) Scr Mater 55:1175

16. Even-Zur OT, Chaim R (2009) J Mater Sci 44:2063

17. Yue M, Wang KJ, Liu WQ, Zhang DT, Zhang JX (2008) Appl Phys Lett 93:202501

18. Zuniga A, Ajdelsztajn L, Lavernia EJ (2006) Metall Mater Trans A 37:1343

19. Grosdidier T, Ji G, Launois S (2007) Scr Mater 57:525

20. Rana JK, Sivaprahasam D, Raju KS, Sarma VS (2009) Mater Sci Eng A 527:292

21. Sasaki TT, Ohkubo T, Hono K (2009) Acta Mater 57:3529

22. Zhang HW, Gopalan R, Mukai T, Hono K (2005) Scr Mater 53:863

23. Kubota M, Wynne BP (2007) Scr Mater 57:719

24. Ye JC, Ajdelsztajn L, Schoenung JM (2006) Metall Mater Trans A $37: 2569$

25. Sirinivasarao B, Oh-Ishi K, Ohkubo T, Hono K (2009) Acta Mater 57:3277

26. Wen HM, Zhao YH, Li Y, Ertorer O, Nesterov KM, Islamgaliev RK, Valiev RZ, Lavernia EJ (2010) Philos Mag 90:4541

27. Zhang ZH, Wang FC, Lee SK, Liu Y, Cheng JW, Liang Y (2009) Mater Sci Eng A 523:134

28. Zhang ZH, Wang FC, Wang L, Li SK (2008) Mater Sci Eng A 476:201

29. Zhang ZH, Wang FC, Wang L, Li SK, Osamu S (2008) Mater Lett 62:3987

30. Schlunegger UP (1980) Advanced mass spectrometry: applications in organic and analytical chemistry. Pergamon, New York

31. Barr TL (1978) J Phys Chem 82:1801

32. Lenglet M, Kartouni K, Machefert J, Claude JM, Steinmetz P, Beauprez E, Heinrich J, Celati N (1995) Mater Res Bull 30:393

33. Mrowec S, Stoklosa A (1971) Oxid Met 3:291

34. Park JH, Natesan K (1993) Oxid Met 39:411

35. Fallberg A, Ottosson M, Carlsson JO (2010) J Cryst Growth 312:1779

36. Wang J, Chen JT, Yuan XM, Wu ZG, Miao BB, Yan PX (2006) J Cryst Growth 286:407

37. Lvov BV, Novichikhin AV (1995) Spectrochim Acta B 50:1459

38. Susegg O, Hellum E, Olsen A, Luton MJ (1993) Philos Mag A 68:367

39. Aikin BJM, Dickerson RM, Jayne DT, Farmer S, Whittenberger JD (1994) Scr Metall Mater 30:119

40. Li Y, Liu W, Ortalan V, Li WF, Zhang Z, Vogt R, Browning ND, Lavernia EJ, Schoenung JM (2009) Acta Mater 58:1732

41. Besenbacher F, Norskov JK (1993) Prog Surf Sci 44:5

42. Soon A, Wong L, Delley B, Stampfl C (2008) Phys Rev B 77:125423

43. Ellmer H, Repain V, Rousset S, Croset B, Sotto M, Zeppenfeld P (2001) Surf Sci 476:95 